\title{
Natural frequencies of the colonnades of the Parthenon Athens at micro tremor level
}

\author{
M. Ohmura ${ }^{1}$, H. P. Mouzakis ${ }^{2}$, M. Ioannidou ${ }^{3}$, \\ A. Militiadou ${ }^{4} \&$ T. Hanazato ${ }^{1}$ \\ ${ }^{I}$ Graduate School of Engineering, Mie University, Japan \\ ${ }^{2}$ Earthquake Engineering Laboratory, National Technical University, \\ Athens, Greece \\ ${ }^{3}$ Acropolis Restoration Services, YSMA, Greece \\ ${ }^{4}$ Hellenic Ministry of Culture and Tourism, Greece
}

\begin{abstract}
Micro-tremor measurements were conducted at the Parthenon Athens, which has survived for 25 centuries against earthquakes, in order to understand the fundamental dynamic characteristics of its colonnades. As the fundamental characteristics, their natural frequencies in both in-plane and out-of plane directions were evaluated. The observed natural frequencies were compared with those of the past study presented in STREMA89. Earthquake monitoring equipment was installed at the Parthenon to study the seismic performance.

Keywords: micro tremor, stone masonry, world heritage, seismic performance, seismic monitoring.
\end{abstract}

\section{Introduction}

As Greece is one of the seismic countries located around the Mediterranean Sea, a number of large earthquakes have hit Athens during its long history. During the last few decades, Athens was affected by the Corinth Earthquake of 1981 and by the Athens Earthquake of 1999. Of these two earthquakes, the Corinth Earthquake caused damage to the Parthenon Athens [1]; however, the Parthenon has structurally survived against earthquakes for 25 centuries [2].

At the first conference of STREMA in 1989, Theofanopoulos et al. [3], Hanazato et al. [4] and Watabe et al. [5] presented the fundamental dynamic characteristics of the Parthenon and the Acropolis hill. In their studies, the 
natural frequencies of the main colonnades were evaluated from the analysis using a simplified lamped masses model. The parameters assumed for the analysis model were identified from the microtremor analysis of Temple of Olympian Zeus Athens [6]. However, it was needed at that time to verify the analysis model. 20 years have passed since their past studies on the seismic safety of the Parthenon Athens. The authors had an opportunity to restart the research as an international collaborative study. The present paper describes the microtremor measurements of the Parthenon Athens to show its fundamental dynamic characteristics. In particular, it focuses on the natural frequencies of the colonnades. In addition, earthquake monitoring to obtain actual data of the seismic performance at earthquake level is outlined.

\section{Microtremor measurements}

Measurements of microtremor were carried out using a total of 6 microtremor sensors, shown in Figure 1. Sampling duration was 60 seconds for each record with a sampling frequency of $100 \mathrm{~Hz}$. A portable monitoring equipment of SPC51A (Tokyo Sokushin Co., Ltd.) was used in the present research.

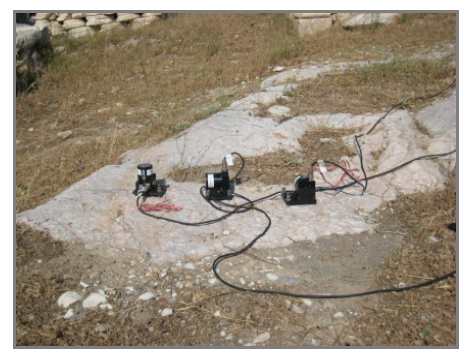

(A)

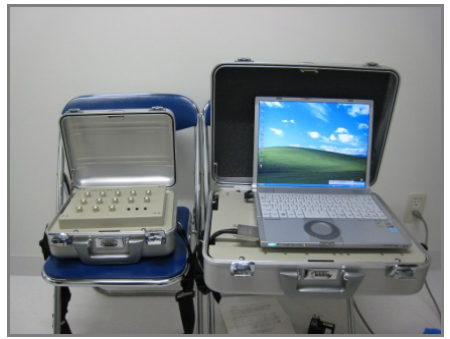

(B)

Figure 1: (A) Microtremor sensors and (B) recording unit.

Figure 2 shows the arrangement of the microtremor sensors at the west, east and north colonnade. A sensor of $\mathrm{CH} 1$ was placed on the base, while the other sensors from $\mathrm{CH} 2$ to 6 were arranged at the top of the frieze. Transfer functions from the base to the top of the beam were calculated to obtain the natural frequencies in both in-plane and out-of-plane directions.

Figures 3 (A) to (E) show the transfer function at the west colonnade in its inplane direction. It can be recognized that the natural frequency of the west colonnade is about $3.3 \mathrm{~Hz}$ in this direction. On the other hand, spectral peaks, shown in Figures $3(\mathrm{~F})$ to $(\mathrm{J})$, were affected by the sensor's location in out-ofplane direction. In these figures, a predominant peak at $2.4 \mathrm{~Hz}$ was found in the spectra observed at the measuring points in the middle $(\mathrm{CH} 3,4$ and 5) of the west colonnade.

It can be found in Figures 4 (A) to (E) that the natural frequency of the east colonnade was $3.7 \mathrm{~Hz}$ in an in-plane direction. The natural frequency of this 

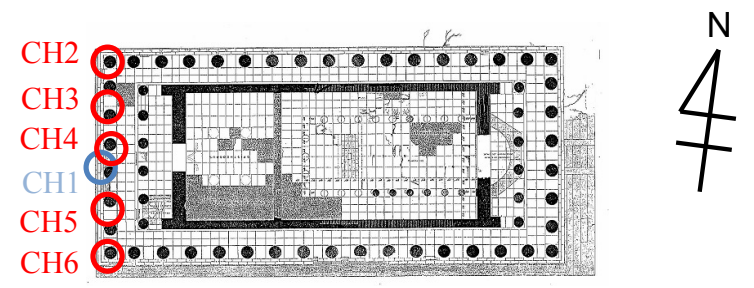

(A)

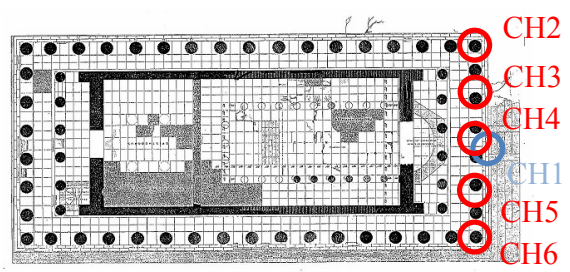

(B)

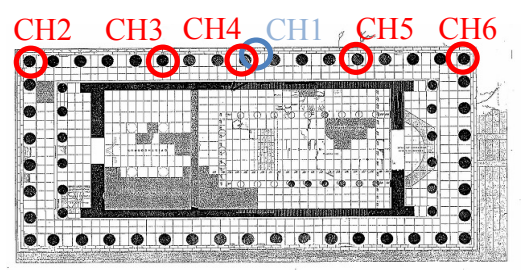

(C)

Figure 2: Arrangement of the microtremor sensors at (A) the west colonnade, (B) the east colonnade, and (C) the north colonnade.

colonnade in an out-of-plane direction was also found to be $2.7 \mathrm{~Hz}$ (shown in Figures $4(\mathrm{~F})$ to $(\mathrm{J})$ ).

Transfer function of the micro tremor records at the north colonnade showed that the natural frequency was $3.7 \mathrm{~Hz}$ for the in-plane behavior, shown in Figures 5(A) to (E). On the other hand, the natural frequency for the out of-plane behavior was not observed clearly (shown in Figures $5(\mathrm{~F})$ to $(\mathrm{J})$ ).

The past study conducted by Theofanopoulos et al. [3] showed that the natural frequencies of the west colonnades were $1.7 \mathrm{~Hz}$ and $3.7 \mathrm{~Hz}$, in the out-of plane and in plane directions, respectively. The measured natural frequency in the in-plane direction is in rough agreement with the past analytical study [3-5]. On the other hand, there was significant difference in natural frequencies in the out-of plane directions between the analysis and the measurement. Hence, its reason was discussed as follows. Uniform deformation of the beam in the out-of plane direction was assumed in the analysis model introduced in the past study [3]. In this assumption, the effect of the constraint at both the corners connecting 


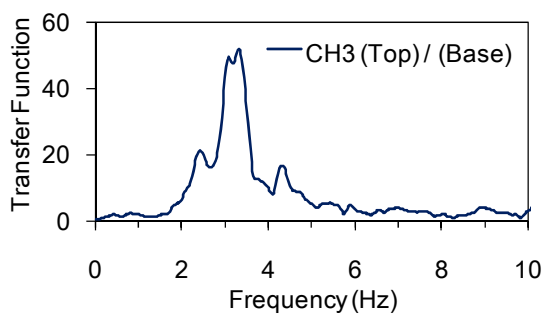

(A)

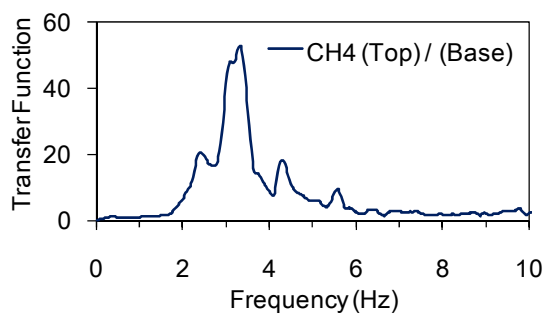

(C)

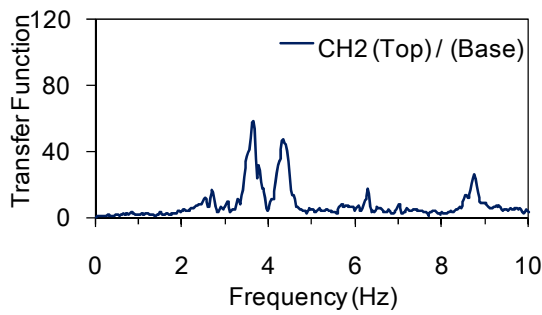

(E)

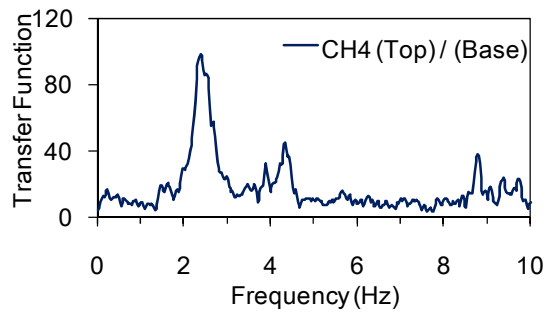

(G)

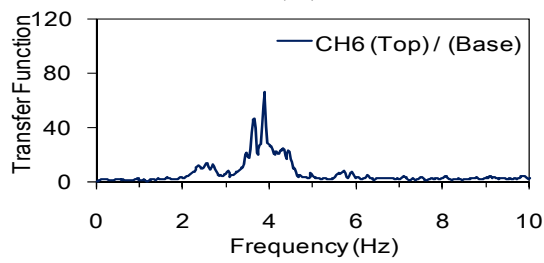

(I)

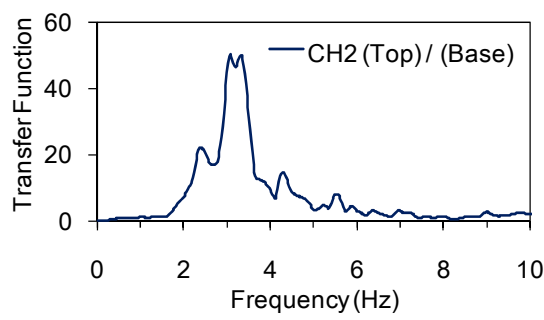

(B)

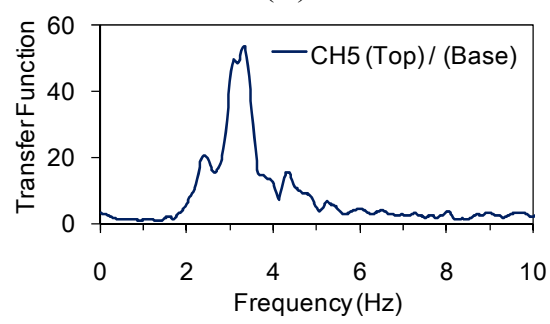

(D)

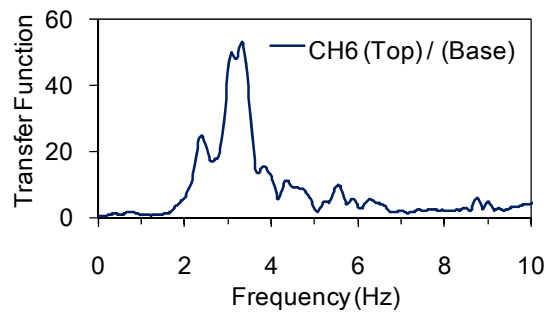

(F)

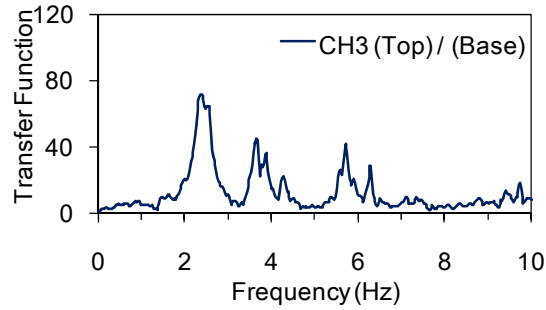

(H)

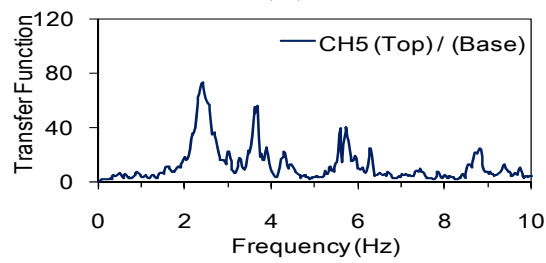

(J)

Figure 3: Transfer function of the west colonnade in (A)-(E) the in-plane, and (F)-(J) the out-of-plane direction. 


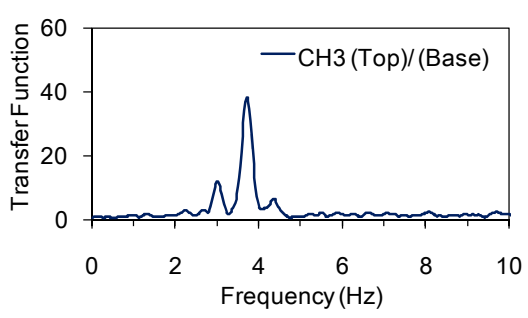

(A)

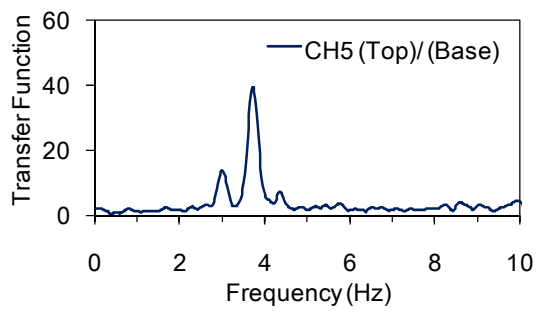

(C)

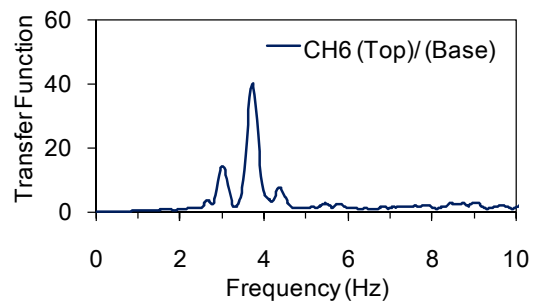

(E)

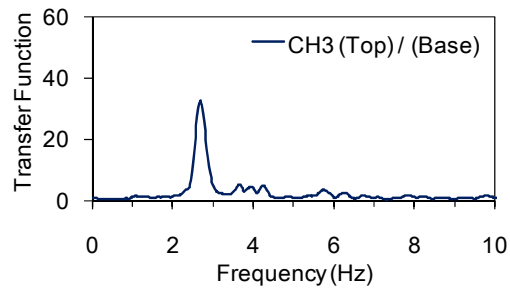

(G)

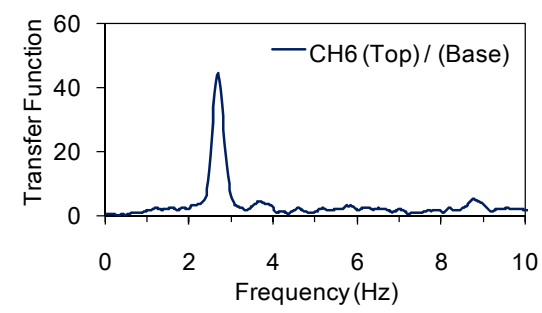

(I)

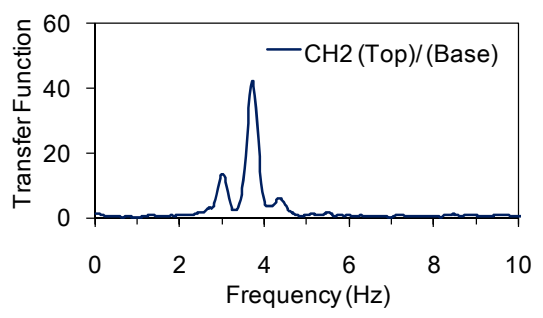

(B)

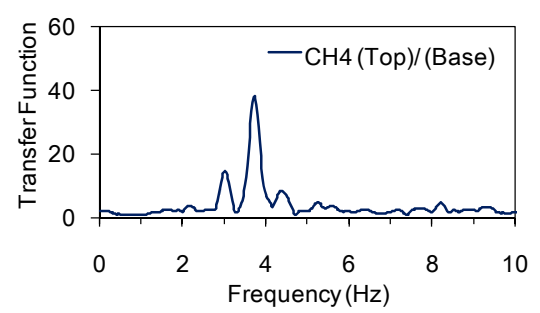

(D)

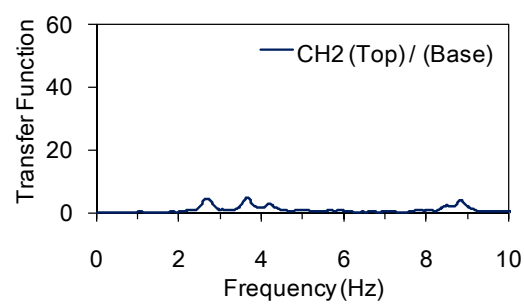

(F)

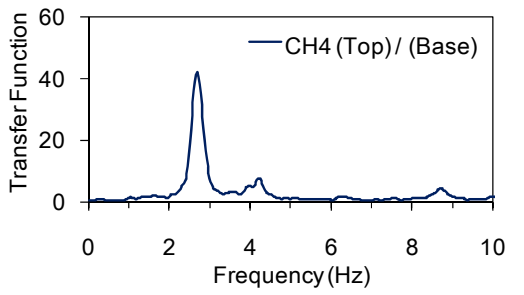

$(\mathrm{H})$

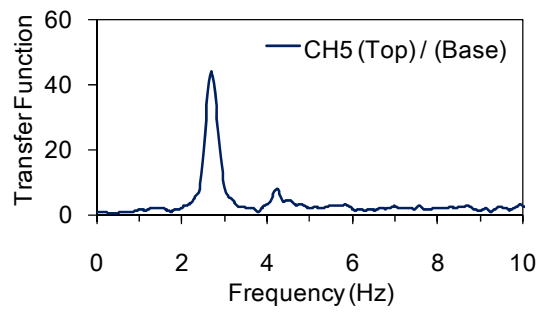

(J)

Figure 4: Transfer function of the east colonnade in (A)-(E) the in-plane, and (F)-(J) the out-of-plane direction. 


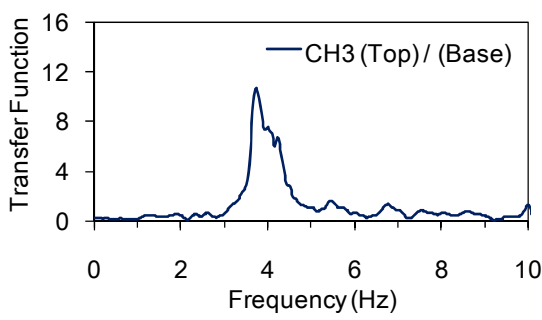

(A)

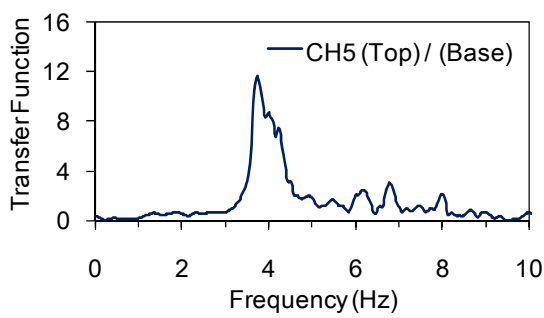

(C)

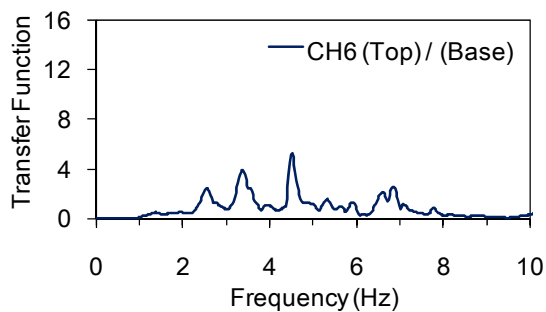

(E)

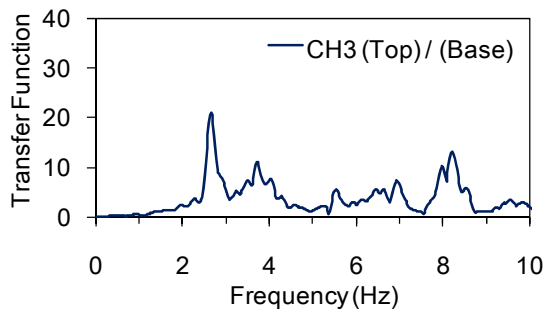

(G)

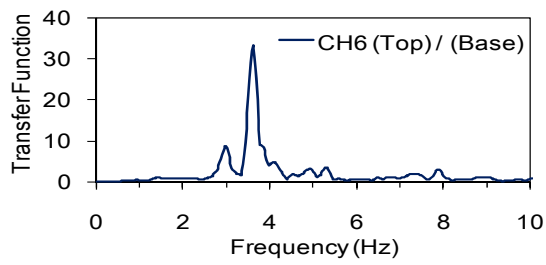

(I)

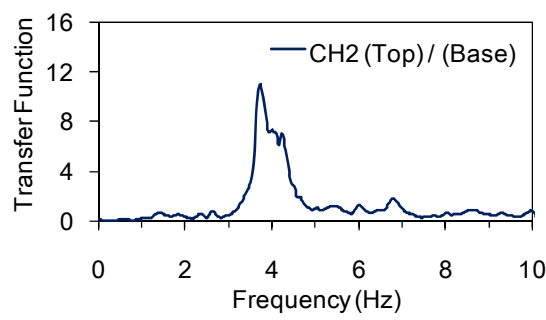

(B)

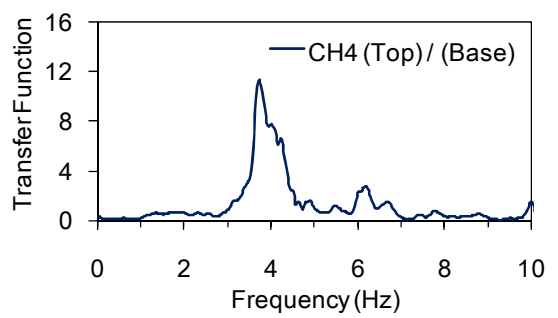

(D)

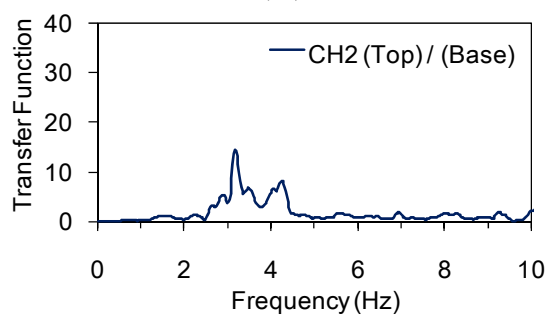

(F)

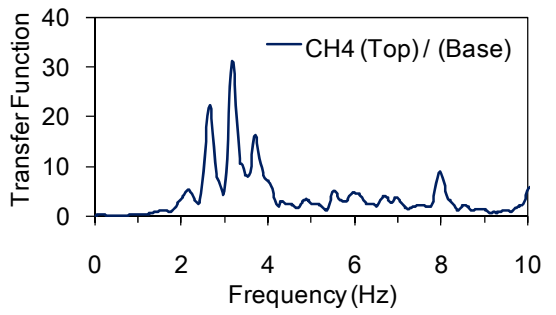

(H)

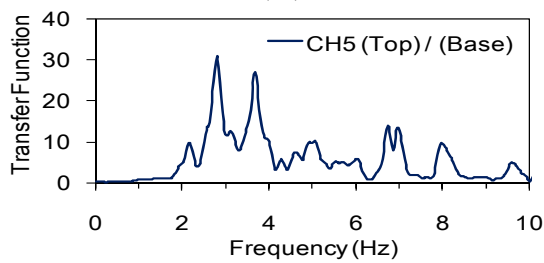

(J)

Figure 5: Transfer function of the north colonnade in (A)-(E) the in-plane, and $(\mathrm{F})-(\mathrm{J})$ the out-of-plane direction. 
perpendicularly to the neighboring colonnades was ignored. However, the actual behaviors (natural frequency and mode) of the colonnades were structurally affected by the boundary conditions at the both corners. Such a difference in the boundary condition caused a difference in the natural frequencies.

\section{Earthquake monitoring}

In September, 2008, two seismograms for earthquake monitoring were installed at the base (master sensor) and at the roof (slave sensor) of the north-east corner, shown in Figure 6.

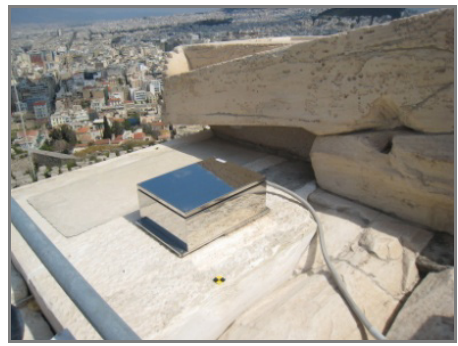

(A)

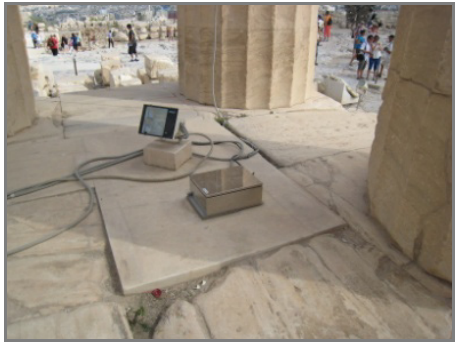

(B)

Figure 6: $\quad$ Servo accelerographs, (A) master sensor and (B) slave sensor.

On $2^{\text {nd }}$ September, 2010, a small earthquake was recorded at the base. The amplitude of that earthquake record was as small as $0.0007 \mathrm{G}$. The predominant period was found in the response spectra at $0.5 \mathrm{~s}$. However, the topographical effect of Acropolis hill on the ground motions still remains as a subject to be studied.

For assessment of the seismic safety of the Parthenon Athens, not only microtremor measurements but also such earthquake monitoring should be essential from an earthquake engineering point of view. It is expected that, in the near future, earthquake data at an appropriate level will be recorded at the Parthenon site.

\section{Concluding remarks}

The microtremor measurements revealed the fundamental natural frequencies at microtremor level as:

1) The natural frequencies of the west colonnade were $3.3 \mathrm{~Hz}$ and $2.4 \mathrm{~Hz}$ in the in-plane and out-of plane directions, respectively.

2) Those of the east colonnade were $3.7 \mathrm{~Hz}$ and $2.7 \mathrm{~Hz}$ in the in-plane and out-of plane directions, respectively.

3) The natural frequency of the north colonnade was $3.7 \mathrm{~Hz}$ in the in-plane direction. 
Those observed natural frequencies were well correlated with the analysis of the past study for the in-plane behaviors. However, there was significant difference between the measurement and the analysis for the out-of plane behaviors. Such caused by the boundary condition of the colonnades at both corners, indicating the necessity to take account the effect of the neighboring colonnades in the analysis model.

\section{Acknowledgement}

The present international collaborative research has been financially supported by Grants-in-Aid for Scientific Research, Japanese Governmental Fund.

\section{References}

[1] Cardis, P. G., Tilford, N. R., Brandow, G. E., \& Jirsa, J. O., The Central Greece Earthquakes of February-March 1981, A Reconnaissance and Engineering Report, Washington, D. C., National Academy Press, 1982.

[2] Brouskari, M., The Monuments of the Acropolis, Ministry of Culture, Archaeological Receipts Fund, Greece, 2006.

[3] Theofanopoulos, N., Hanazato, T. \& Watabe, M., Seismic Response Analysis of Parthenon Columns, Proc. of the 1st International Conference on Structural Repair and Maintenance of Historical Buildings (STREMA89), pp. 339-348, 1989.

[4] Hanazato, T., Mabuchi, Y., Theofanopoulos, N. \& Watabe, M., Earthquake Resistant Capacity of Parthenon, Proc. of the 9th Japan Earthquake Engineering Symposium, pp. 2007-2012, 1990.

[5] Watabe, M., Aoki, H., \& Hanazato, T., Earthquake Resistant Capacity of the Parthenon, Proc. of the International Association for Bridge and Structural Engineering Symposium (IABSE), pp. 345-352, 1993.

[6] Theofanopoulos, N., Hanazato, T., Matsukawa. K. \& Watabe, M., Analysis of Microtremor Records at Zeus-Olympeion Athens and Assessment of its Safety by Employing Dynamic Response Analysis, Proc. of the 1st International Conference on Structural Repair and Maintenance of Historical Buildings (STREMA89), pp. 319-328, 1989. 